\title{
INVESTIGANDO SOBRE VIOLENCIA DELINCUENCIAL EN VENEZUELA
}

\author{
RESEARCHING ABOUT DELINQUENT VIOLENCE IN VENEZUELA
}

\author{
Alejandro Moreno $0^{1}$ \\ Centro de Investigaciones Populares, Caracas, Venezuela \\ (RECIBIDO, 29/09/2011, ACEPTADO 29/11/2011)
}

\begin{abstract}
RESUMEN
El autor, quien lleva viviendo desde hace más de treinta años, en un barrio marginal de Caracas, ha investigado y publicado varios artículos y libros sobre el mundo-de-vida popular venezolano y ha fundado y dirige el Centro de Investigaciones Populares (CIP), presenta un breve pero completo informe sobre la violencia delincuencial y asesina de Venezuela sobre la base de una amplia investigación de tipo cualitativo mediante historias de vida. A partir de ese trabajo, con su equipo ha podido elaborar un perfil del delincuente violento de origen popular del cual en este texto ofrece los principales resultados.
\end{abstract}

Palabras claves: violencia delincuencial, delincuente popular, historia-de-vida, respeto, forma-de-vida, Venezuela

\begin{abstract}
The author, who has lived up to 30 years in Caracas' poor neighborhoods and written many articles and books with the Popular Investigations Centre's team (by him founded and directed), offers a brief, but complete inform about assassin violence in Venezuela. After a quick review of the main quantitative aspects, he studies in depth the qualitative dimension of this phenomenon, approaching the violent subjects' closer motivations. Once ruled out easy causal interpretations, and detected the well founded personal/social origins of that violence, the author suggests some possible corrective interventions.
\end{abstract}

Key Words: Delinquent violence, popular delinquent, history-of-life, form-of-life, respect, Venezuela.

1 Director del Centro de Investigaciones Populares, Caracas, Venezuela Docente jubilado de las universidades : Universidad Católica Andrés Bello, y Universidad de Carabobo de Caracas, Venezuela E-Maill: cip@cantv.net 


\section{INTRODUCCIÓN}

El Centro de Investigaciones Populares es, como su nombre lo indica, una institución dedicada al estudio y conocimiento comprensivo del mundo-de-vida presente en las prácticas cotidianas de los sectores populares venezolanos. Fundado por quien les habla hace veintiocho años, en él hemos abordado, por exigencias de la misma realidad, dado que todos los investigadores habitamos por decisión propia en los ambientes de barrio que investigamos, en primer lugar la estructura de la familia popular como fenómeno cultural y en ella el sistema de significados que dan razón de la manera de ejercer la vida e identificarse con ella del hombre y la mujer en su cotidianidad.

Desde 1995 el Centro publica una revista bajo el título de "Heterotopía" en la que se abordan tanto temas epistemológicos y teóricos, especialmente referidos al movimiento cualitativo en investigación, como propuestas metodológicas e informes sobre investigaciones realizadas.

A parte de la revista, hemos sacado a la luz numerosas otras publicaciones. Tenemos que decir, sin engañarnos y sin dejarnos llevar por una falsa modestia, que hoy cualquier estudio que se emprenda sobre la familia y el mundo-de-vida popular venezolanos tiene ineludiblemente que contar con nuestras investigaciones. De ahí ha resultado que casi todas nuestras publicaciones se han agotado antes de lo esperado y han tenido que ser reeditadas incluso más de una vez. Entre ellas se destacan: "El Aro y la Trama: episteme, modernidad y pueblo" (Moreno, A. 2009) $5^{\text {a }}$ edición, "La Familia Popular Venezolana” (Moreno, A. 2007), $3^{\text {a }}$ edición, "Historia-de-vida de Felicia Valera" (Moreno, A. Et Alt. 1998), agotada y en reedición, "Buscando Padre" (Moreno, A. Et Alt., 2002), agotado y en reedición, “Padre y Madre?” (Moreno, A., 2008), 2 a edición, son materia de consulta y estudio en los ambientes universitarios de todo el país y de las instituciones de todo tipo que tienen que ver en su actividad con nuestra población.

Nuestras investigaciones nos han llevado a definir el mundo-de-vida popular venezolano como un sistema de significados sostenido sobre unas prácticas comunes a todos los convivientes del mismo, apoyadas a su vez sobre una práctica primera de la que todas las demás reciben el sentido y que actúa como centro dinámico de organización que conforma como mundo total la vida de las comunidades populares venezolanas. Esta práctica primera conformadora del mundo-de-vida es la relación convivial de tono matricentrado afectivo. Por eso caracterizamos al hombre venezolano popular como homo convivalis que se comprende estructuralmente no como un individuo sino como una relación.

Según esto, lo propiamente característico, lo de alguna manera identificatorio en la estructura relacional de nuestro pueblo, lo cultural en profundidad raigal, es la convivialidad abierta al encuentro positivamente afectivo en el que los conflictos se resuelven por el acuerdo y la búsqueda espontánea de entendimiento. Su expresión en la práctica societaria del vivir, por su normalidad, no produce cuestionamiento. Lo que, en cambio, cuestiona y exige explicación, es su contrario: la exclusión, la agresión, la violencia. Lo que pide respuesta, es esa agresividad que en estos 
días parece haber invadido los lugares de la convivencia popular y haber saltado a ocupar los espacios de lo público y lo social.

Una vez desarrollados con amplitud y consistencia estos conocimientos y puestas así las bases para interpretar comprensivamente nuestra realidad humana, nos abocamos a incursionar en algunos aspectos más particulares y específicos de la misma. En varias tesis de maestría y doctorado dirigidas por el personal del CIP y otros trabajos se han enfocado temas como la educación, la orientación psicológica y educativa (Moreno, A. y González, V., 2008), la familia venezolana en su historia (Moreno, A. 2006; Pérez, M., 2010), el estudio de los valores, la religiosidad y otros muchos.

En este contexto, se destaca como fenómeno específico e inquietante, la violencia delincuencial en los sectores populares: ¿cómo puede ser comprendido a partir de las bases ya puestas por nosotros en los trabajos mencionados el delincuente violento popular?

\section{LA VIOLENCIA ACTUAL EN TÉRMINOS CUANTITATIVOS}

Los datos más actuales nos dicen que en lo cuantitativo, si comparamos la encuesta de victimización realizada por el Instituto Nacional de Estadística el año 2006 (INE, 2006) con la que el mismo Instituto ha completado en 2009 (INE, 2010), públicamente conocida por filtraciones a la prensa, dado que estaba destinada a mantenerse secreta, puesto que desde el año 2005 el Estado ha decidido no dar informaciones, arrojó para el año 2009 la cifra de 19.113 homicidios, (Molina, T. 2010) lo que indica que la tasa por cien mil habitantes ha pasado de 49,60 a 75,08. Habría aumentado, según esto, 25,48 puntos en tres años. En el área metropolitana de Caracas la misma estaría, según esos datos, en 233 siendo que la mundial gira en torno a los 9 puntos. Cifras estrictamente oficiales. Si, por otra parte, consideramos que, según cálculos aceptados, por cada asesinado se producen tres heridos de los que uno de cada siete muere luego, lo que no entra en las estadísticas, la cifra aumenta casi en mil unidades. Como indica Luis Cedeño, de "Paz Activa", mientras las lesiones personales y las amenazas bajaron, --quizás más bien bajó la denuncia--, los delitos más graves aumentaron en un 70\% . "Esto podría significar que los hampones prefirieron matar a sus víctimas antes que hacer advertencias" (Cedeño, L. 2010). El Observatorio Venezolano de la Violencia, de la Universidad Central de Venezuela, dirigido por Roberto Briceño León, a partir de informes de prensa y filtraciones de los cuerpos de seguridad, es más conservador para el mismo período (año 2009) calculando la cantidad de homicidios en 16.047, mientras suma para el año 2010 un número de 17.600 muertes violentas en todo el país (Briceño, R. 2010). Mis cálculos particulares, siempre sobre informes de prensa y sólo para la ciudad de Caracas, desde el 1 de enero hasta el 15 de abril de este año 2011, dan un promedio de 39 asesinatos para cada fin de semana. Al sintetizar en una cifra las muertes violentas acaecidas en Venezuela en los diez últimos años, hallamos que está cerca de las 145.000. Unos las calculan en torno a los 125.000 (Rodríguez, G., 2010) mientras hay quien las lleva hasta 155.000, 
cifra negada por el Ministro del Interior según noticia de agencia (EFE, 2011). Se suelen establecer comparaciones con las muertes acaecidas en períodos de tiempo semejantes en países en guerra o con serios conflictos bélicos -El Salvador, Colombia y otros- y Venezuela las supera.

Ya para el 2005, cuando el gobierno decidió no proporcionar cifras sobre violencia, Briceño León señalaba (Briceño, R., 2005, 110): “en dos décadas la población no se duplicó, pero los homicidios se multiplicaron por diez. El número de homicidios ocurridos en el país, que a comienzos de los años ochenta oscilaba alrededor de los 1.300 muertos, superó veinte años después, los 13.000 asesinatos".

La fuerza de esta violencia es relativamente reciente. Cuando todavía en 1989 se le propuso al Rector de la Universidad Católica Andrés Bello (UCAB) y al equipo de investigación de la misma participar en un estudio conjunto sobre la violencia en América Latina (Ugalde, 1993, 7), los venezolanos pensaron que no era necesario pues ése no era un problema suyo. Apenas dos años después durante los cuales se trabajó en el proyecto la realidad había cambiado dramáticamente tanto en los hechos como en la percepción de los investigadores (idem).

Sin embargo, en ese mismo año de 1989 y comentando los acontecimientos de saqueos y violencia callejera desatados en toda la nación el 27 de febrero, a raíz del aumento del precio de la gasolina y el desabastecimiento de artículos de primera necesidad, el apreciado psiquiatra José Luis Vethencourt $(2008,53)$ advirtió: "Es presumible un gran malestar en el seno de los grupos familiares golpeados por la situación; también es presumible un intercambio de agresiones entre la gente en la calle y por último parece evidente el aumento de la violencia delictiva (...) sobre todo en la clase media baja y mayoritariamente en el estrato de la creciente pobrecía (...) Sería ésta una manera de vivir en la violencia crónica, sin salida aparente, que amenaza a las grandes mayorías de la sociedad”.

En Venezuela siempre se conoció, como en la mayoría de los países, la violencia propia del medio rural, esa que sobreviene al calor de los tragos, por explosiones de furor, por rencillas de honor entre machos ofendidos, por inveteradas hostilidades entre clanes y familias enfrentadas a raíz de algún reparto de herencias, ocupaciones de tierras, movimiento de linderos o marcaje de ganado. Era la violencia caliente, pasional, orientada a la víctima bien identificada. La urbana, en cambio, nos era poco conocida. Surgía muy de tarde en tarde, como excepción, en situaciones inesperadas y sorpresivas. Estábamos en un país en el que para mediados del siglo $\mathrm{XX}$ el ochenta y cinco por ciento de la población vivía en el campo.

A partir de los años cincuenta, cuando el petróleo, que ya venía desde 1922 siendo el factor preponderante en la economía del país, se convirtió en la principal fuente de trabajo y de enriquecimiento especialmente en las ciudades, se produce un masivo movimiento de emigración del campo a las periferias ciudadanas de modo que al final del siglo se han invertido las proporciones: sólo el quince por ciento ahora vive en el campo. El proceso se llevó a cabo en forma pacífica. "La Venezuela que se urbanizó aceleradamente entre los años cuarenta y sesenta del siglo XX, estaba, al mismo tiempo, construyendo una sociedad sin violencia. Era un país 
que apostaba al Estado de Derecho como la respuesta adecuada a las necesidades de convivencia y resolución de conflictos de la sociedad que se modernizaba" (Briceño León, R. 2005, 110).

En el nuevo escenario urbano, la primera fue la violencia política, el asesinato de opositores durante la dictadura y luego el de funcionarios de gobierno, humildes policías entre otros, en tiempos de la guerrilla por los años sesenta, una violencia dirigida e instrumental, como la ha llamado Ugalde (1993, 7), esto es, utilizada como medio específico para conseguir fines bien definidos. Era una violencia que se explicaba por sí misma. No planteaba problemas de comprensión sino sólo de justificación.

En estas dos últimas décadas, en cambio, estamos asistiendo a una violencia asesina que no parece tener dirección ni instrumentalidad precisa y que, en palabras de Luis Pedro España, investigador de la $\operatorname{UCAB}(1993,14)$ "no nace de grupos de interés o facciones políticas, económicas o culturales que decidan usar la violencia para defenderse o dominar a la comunidad. Por el contrario, se trata de acciones y reacciones desproporcionadas al contexto en que ocurren y carentes de objetivo específico o que transcienda más allá de alguna necesidad del agresor directo", una violencia que, en palabras del mismo autor, "se ha vuelto loca" (p.13) porque "no conoce de normas o de racionalidad que permita dialogar con ella" (p. 14).

Esta es, entonces, una violencia que ahora no plantea problemas de justificación, porque por definición es injustificada ya de partida, pero sí problemas de comprensión.

¿Qué significa esa locura? ¿Es de veras totalmente irracional en sí misma o dispone de una racionalidad intrínseca, una lógica interna, que nos permita comprender su nacimiento, su curso y su desembocadura y pensar por tanto en márgenes, diques, desagües y rectificaciones?

\section{DEFINICIÓN DEL OBJETO DE INVESTIGACIÓN}

¿Pero a qué tipo de violencia me voy a referir? En momentos como estos por los que la sociedad venezolana está hoy atravesando, es ineludible establecer prioridades. Entre los múltiples tipos de violencia existentes, la que borra de la vida a tantos venezolanos cada día y la que nos amenaza a todos, exige ser aquella sobre la que dirijamos el foco de nuestra atención y nuestro análisis. Ella, en el ámbito popular de nuestros días, ha sido objeto de un estudio detenido en nuestro Centro de Investigaciones Populares y tema de una amplia publicación y difusión (Moreno, A. et Alt. 2009).

Dentro de la clasificación de las distintas violencias que hace la OMS (WHO, 1996; OMS 2002) hemos centrado nuestro esfuerzo sobre la que hemos definido como violencia no fortuita, intencionada por tanto, física, hasta el extremo de producir muerte, y no justificada, esto es, no en defensa propia, por ejemplo, y por ende delictiva. 


\section{ANTECEDENTES EN LA INVESTIGACIÓN}

La violencia delincuencial en Venezuela ha sido objeto de numerosas investigaciones e intercambios de ideas entre los científicos sociales, los políticos, los religiosos y la población en general justamente preocupada por su aumento, difusión y peligrosidad. El tema de estudios y reflexiones ha girado sobre todo en torno a los aspectos cuantitativos y estadísticos del fenómeno (Briceño-León, R. et alt. 1997; Briceño-León, R. y Pérez Perdomo, R. 2002, Briceño León, R. 2005, 2007, 2008) y a las explicaciones de tipo psicológico (Vethencourt, J. L. 1990, 2008; Pedrazzini, Y., y Sánchez, M., 1990, 1992) sociológico (Briceño-León, R. 1997, Cisneros, A. y Zubillaga, V., 1997, Zubillaga, V., 2008), antropológico (Ferrándiz, F. 2005) criminalístico (Del Olmo, R. 1997) y también multidisciplinario (Briceño-León, R. 2001) a partir de teorías asumidas como de valor universal pero no elaboradas teniendo en cuentas el modo de ser y de vivir específicamente venezolanos, lo propiamente cualitativo.

Cuando de bucear en las fuentes y causas de esta mortal agresividad se trata, la atención del estudioso fácilmente se ha ido a explorar por los amplios campos de la violencia en cuanto tal y por los de las grandes causas generales que pueden identificarse como sus productoras. Se destaca la violencia estructural de la sociedad humana en sus distintas realizaciones históricas y la propia de las situaciones de exclusión, opresión, pobreza e injusticia dominantes en América Latina y en nuestro país. La lista de causas y condiciones que se conectarían con la violencia delincuencial de nuestros días puede ser casi interminable.

Es bien conocido que para ningún fenómeno, acontecimiento o proceso social puede hablarse de causas, ni una ni muchas, en sentido estricto. Hay que hablar más bien de circunstancias, condiciones, tendencias, posibilidades o probabilidades múltiples, diversas, coincidentes, interrelacionadas y a lo sumo regidas, no determinadas, por una motivación, una integración de experiencias compartidas, un factor social o un conjunto de ellos excepcionalmente activo, capaz de marcar una orientación predominante al fenómeno en cuestión.

A la llamada violencia estructural de la sociedad concreta, dígase capitalista y explotadora o tenga cualquier otra especificación, están sometidas todas las personas de esa sociedad pero sólo una mínima parte de ellas es delincuente violento. Es la conducta de este pequeño porcentaje la que hay que explicar. La violencia estructural, para el caso que nos ocupa, explica demasiado y por tanto no explica nada.

Lo mismo puede decirse de la situación general de los sectores populares y las condiciones de pobreza y exclusión en las que se considera que viven. Ellas afectan a todos los venezolanos de esos sectores, pero sólo una mínima parte de sus componentes se dedican al delito violento. La pobreza y la exclusión, lo mismo que otras condiciones de la vida popular, no lo explican. No explican qué sucede para que Héctor Blanco, uno de los sujetos de nuestra investigación, pueda decir: "cuando tenía quince años, ya tenía seis homicidios" (Moreno, A., et Al., 2000, 314) o en otro momento: "a partir de los catorce años me empecé a meté 
en problemas, empecé a dale tiros a la gente" (Idem, 309) y, en cambio, Ismael (Moreno, A., et Alt., 2009, 798-825), abandonado y sin familia desde los tres años, no sólo nunca haya matado a nadie sino que hoy sea un dedicado educador de niños en situación de calle.

La sociedad en la que ambos han vivido ha sido la misma sociedad opresora, corrupta, explotadora y violenta estructuralmente y las circunstancias de exclusión y marginalidad han sido para Ismael aun peores que para Héctor.

\section{APROXIMACIONES TEÓRICAS}

Es aquí donde la psicología social, unida a la antropología cultural urbana, a la sociología, a la reflexión filosófica situada en lo concreto y a la comprensión hermenéutica de la realidad vivida, puede ayudarnos a explicar y sobre todo a comprender.

En buscar comprensión ha consistido una amplia investigación desarrollada durante cinco años, desde el 2001 hasta el 2007 y financiada por el FONACIT, instituto nacional para la promoción de la ciencia y la tecnología, en el Centro de Investigaciones Populares (CIP) que quien de esto habla fundó y dirige desde hace veintiocho años. El producto editorial ha sido una obra en dos volúmenes titulada $Y$ salimos a matar gente: investigación sobre el delincuente violento venezolano de origen popular (Moreno et Alt. 2009).

\section{APROXIMACIONES METODOLÓGICAS}

Es verdad que se ha acumulado conocimiento relativamente abundante sobre los aspectos estadísticos y generales de esta problemática, pero a quienes vivimos desde largos años en contacto con muchos de los actores de la violencia delincuencial, que hemos no sólo presenciado sino experimentado vivencialmente su evolución en los ambientes populares que habitamos y que por otra parte hemos dedicado tiempo y estudio a la comprensión del mundo-de-vida popular venezolano, se nos han planteado otras preguntas, preocupaciones y enfoques.

Hay que decir que se conoce la violencia desde fuera de sus actores, pero ¿cómo es ella desde dentro de los propios sujetos violentos? Si, viviendo en las mismas circunstancias, la gran mayoría de la gente no cae en el delito asesino, ¿qué personas caen en él? ¿Cómo son? ¿Cómo se relacionan? ¿Cuáles son sus profundos deseos? ¿Cuál es su proyecto vital?

Ahora bien, planteado así el problema, ¿dónde buscar este mundo interno, si no en toda por lo menos en el máximo posible de su complejidad?

Y en segundo lugar, una vez encontrado ese dónde, ¿cómo abordarlo de manera que se pueda llegar no sólo a una descripción sino a una comprensión de la dinámica interna, de la lógica, si existe alguna, que rige su desenvolverse y su estar en el mundo? 
En el fondo, esto es lo mismo que plantearse como objeto de nuestra preocupación la vida de los sujetos violentos en toda su integridad. Ahora bien, esa vida está en ellos y no sólo en el plano individual sino también en el plano del grupo o del tipo de "los violentos asesinos" y en el del mundo-de-vida popular al que pertenecen pues son los violentos de origen popular en los que, por ahora, nos hemos centrado.

Si, como dice Franco Ferrarotti (1981), cada persona es la síntesis de lo social en lo individual, de lo general en lo particular; si, además, en cada sujeto están no sólo la sociedad a la que pertenece sino todos los grupos por los que ha pasado en su vida y en los que ésta discurre, y si, por tanto, en una persona se puede conocer toda una sociedad, ese donde que hemos buscado es la vida de cada uno de los actores. Esa vida, por otra parte, está entera y en plenitud en su historia. En la historia-de-vida de cualquiera de los violentos asesinos podemos hallar esa violencia desde dentro y en su concretez vital.

Hemos seleccionado, así, quince historias-de-vida de asesinos de origen popular de distintos lugares de Venezuela y de distintas edades, todos varones. El estudio sobre mujeres está en proceso. El número obedece al deseo de encontrar variedades y contrastar diversidades.

Los sujetos provienen de las distintas zonas del país: Caracas, Miranda, Maracaibo, San Cristóbal, Valencia, Cumaná, Ciudad Bolívar. Todo el país está representado en su diversidad regional. Unos han sido contactados en la cárcel, otros en las comunidades populares en las que viven; los más jóvenes en institutos para menores. Unos son conocidos desde tiempo antes por los investigadores, con otros se ha establecido una relación previa durante largo tiempo encaminada a lograr la confianza necesaria para obtener la narración de su historia-de-vida.

Las historias-de-vida son, pues, el dónde hemos buscado la violencia asesina desde su hacerse hasta su presencia en el momento en que la historia es narrada por su actor, a quien llamamos historiador y no entrevistado o informador, ante un cohistoriador que no entrevistador o investigador.

Estamos de lleno en el ámbito de la investigación cualitativa en cuanto la investigación cualitativa se centra en lo que distingue, identifica y caracteriza como totalidad a la realidad bajo estudio como ya lo dijo Aristóteles en el libro V de la Metafísica, capítulo 14 (1973); "cualidad es la diferencia o característica que distingue una substancia o esencia de las otras".

La orientación cualitativa puede resumirse muy sintéticamente en estas expresiones de M. Martínez $(1999,173)$ : "De esta manera, la investigación cualitativa trata de identificar la naturaleza profunda de las realidades, su estructura dinámica, aquella que da razón plena de su comportamiento y manifestaciones".

Ha sido necesario el vuelco epistemológico de los últimos años que reivindica la subjetividad como forma de conocimiento para que la historia de vida vuelva a ser considerada como de pleno valor científico ${ }^{2}$.

2 Aquí hay que incluir a todos los grandes epistemólogos del siglo XX. Ellos sacan las consecuencias de y aplican a la ciencia esa sensibilidad vital que se ha venido afirmando y de la que Ortega se hace uno de los primeros testigos en El 
Con las historias de vida y los materiales biográficos en general se investiga de muy diversas maneras. La menos "biográfica" de todas ellas es la de aquellos que se sirven de los datos biográficos para completar investigaciones de tipo cuantitativo basadas en encuestas o sondeos con base estadística. La historia de vida, así, se convierte en un adorno no necesario ni de primera importancia puesto ahí, como dice Ferrarotti $(1981,39)$ "para edulcorar los rigores de las medidas cuantitativas exactas".

Otros se sirven de las historias de vida para ilustrar con ejemplos cualitativos y como corroboración anecdótica lo que se ha investigado por otras vías.

En otros casos, las historias o los relatos de vida son tomados como fuente de datos y utilizados para encontrar en ellos lo que se busca más allá de ellos.

Puede, sin embargo, pensarse en una investigación en la cual la historia de vida no sea utilizada para otra cosa más allá de ella misma, una investigación en la cual la historia de vida sea lo que se ha de investigar. Centrarse en la historia de vida como en el qué de la investigación es la posición sostenida y ampliamente desarrollada por F. Ferrarotti para aprovechar toda su potencialidad heurística. Según él $(1981,4)$, "la historia de vida es la contracción de lo social en lo individual, de lo nomotético en lo idiográfico". Siendo esto así, en la vida de cada cual está toda su sociedad vivida subjetivamente que es la única manera de ser vivida que una sociedad tiene, pues una sociedad existe en sus miembros o no existe en absoluto. Esto es lo que justifica poder leer o descubrir toda una sociedad en una historia de vida.

Sin embargo, la cosa es un poco más compleja de lo que el mismo Ferrarotti parece indicar. En mucho depende de qué es lo que se busca en la historia de vida o con la historia de vida. En la mayoría de los casos se han buscado y se buscan datos, esto es, hechos comprobables, objetivos, sea este término entendido en sentido fuerte o en sentido débil.

Cuando se buscan datos en las historias de vida, surgen todos los problemas que los datos plantean en cualquier método o enfoque investigativo. Sobre todo la confiabilidad de los mismos.

La confiabilidad tiene su manera de ser afrontada en los métodos cuantitativos. En cada método cualitativo ha de ser resuelta por vías específicas. En general, de todos modos, la confiabilidad se resuelve por la contrastación entre datos, sea por número, sea por repetición, sea por confirmación de nuevos y otros con respecto a aquellos bajo examen. Si se buscan datos, muchos autores, en el fondo apegados a un criterio tradicional de objetividad, piensan que hay que multiplicar

Tema de nuestro Tiempo, curso dictado en Buenos Aires en 1923.

Así, tenemos a Kuhn con la renovación del concepto de paradigma, a Prigogine con la introducción de la historia en la física y la química, a Bachelard, un pionero, a Lakatos con su teoría de la ciencia como una sucesión de "programas científicos de investigación", a Edgar Morin con la reformulación total del método y la insistencia en el pensamiento complejo, a Feyerabend con la crítica radical al método tradicional y al concepto y la práctica de la ciencia en general, al segundo Popper, con su apuesta por el indeterminismo, a Laszlo al introducir en la ciencia contemporánea la categoría histórica de hecho y, entre nosotros, a Miguel Martínez con su formulación del "paradigma emergente" como núcleo estructural de la "nueva ciencia". 
las historias de vida.

Además de Ferrarotti, M. Catani (1982) y la mayoría de los investigadores de la escuela italiana y la francesa consideran que es suficiente una sola historia incluso cuando se buscan datos.

L. V. Thomas en el prefacio a la obra de Catani, Tante Suzanne (1982, II-III), y en referencia a ella, lo justifica mediante tres formas de validación cada una de las cuales es independiente de las demás. Traduzco y reproduzco: "Las referencias a la vida cotidiana son lo suficientemente numerosas como para designar, más allá de las características personales, un modo de vida... avaladas además por la descripción de la vida cotidiana (del pequeño pueblo)... la segunda forma de verificación es ofrecida por los encuentros con los contemporáneos del narrador: se constata una convergencia que reenvía directamente al sistema de valores, cuando aparecen las mismas opciones a propósito de situaciones diferentes... La observación constituye, finalmente, una tercera forma de verificación... las entrevistas de control se escalonan durante diez años y contienen siempre, bajo aspectos anecdóticamente nuevos, la referencia a los mismos valores...". Estas son formas de verificación centradas en la historia en cuanto material primario sin ningún recurso a materiales secundarios.

Nuestra posición coincide con la de Ferrarotti y los más contemporáneos pero va más allá en cuanto, sin despreciar los datos para la validación de los cuales seguimos las “formas" señaladas por L.V. Thomas, nos centramos en los significados.

$\mathrm{Si}$, en efecto, en vez de centrarse en los datos, la investigación se centra en la historia misma de vida sin buscar nada distinto de lo que ella comunica sino el sentido que en ella está presente y que pone las condiciones de posibilidad para que sea la que es y no otra, el investigador se encontrará de frente con los "significados" que construyen esa vida y esa historia. Si en vez de centrarse en los datos, se centra en los significados, esto es, en esos “complejos" socio-culturales que a partir de las prácticas de vida comunes a un grupo humano determinado (comunidad o sociedad) y participadas por todos sus miembros, se constituyen como integraciones de esas mismas prácticas, de experiencias, valores y representaciones sociales idiosincrásicas del grupo y por lo mismo generales (nomotéticas) en todos y cada uno de dichos miembros, bastará una sola historia, pues en cada persona está la cultura y cada persona está en su cultura.

La persona que narra su historia, tiene control sobre muchos de los datos de esa historia, esto es, al disponerse a narrarlos, tiene conciencia de ellos y por lo mismo controla si los va a narrar o no y cómo los va a narrar. Sobre otros no lo tiene ya sea porque los ha olvidado, ya sea porque "se le salen" sin querer, ya sea porque están distorsionados en su memoria, pero sobre los significados no tiene ningún control pues están presentes en toda su vida y en toda su forma de narrarla: en el lenguaje, en la organización, en el ritmo de la narración, en la veracidad tanto como en la falsedad consciente o inconsciente de lo narrado, etc., etc. La persona no posee los significados sino que es poseída por ellos. En este sentido, Ferrarotti tiene razón cuando afirma que la sociedad está en cada persona; sólo se trata, por 
parte del investigador, de descubrirla.

Ahora bien, ¿cómo acceder, en la historia-de-vida a los significados que constituyen el sentido de la misma y encontrar en ellos toda una realidad social?

Esto nos lleva inevitablemente a la hermenéutica como método general e instrumento práctico de acceso. No ya como filosofía o teoría estrictamente filosófica aunque todo ello pueda estar de fondo

El proceso hermenéutico mediante el cual una realidad social es conocida en sus significados y en los datos que en esos significados tienen su sentido, consta de tres momentos que se dan simultáneamente en un proceso de interacción.

El primero es la interpretación propiamente dicha.

Consiste en dar sentido y significado a lo que todavía no lo tiene en la experiencia del intérprete, el investigador en nuestro caso. Esto es conocer o hacer pensable una realidad. En términos práctico-concretos, interpretar consiste en integrar de manera coherente o no contradictoria lo nuevo en el sistema de relaciones de significado que constituyen el horizonte de quien conoce. Es lo que hace un investigador cuando la nueva realidad que quiere conocer la sitúa en un marco teórico determinado y la somete a procedimientos metodológicos dictados por la práctica aceptada.

Un horizonte para la interpretación, hermenéutico, está constituido por todo el sistema de símbolos, estructuras, matrices del pensar, contenidos culturales de referencia, convicciones asumidas, incluso fuera de la conciencia, comunes a todos los que comparten con nosotros existencia social, paradigmas de todo tipo, representaciones, conceptos, actitudes y todo aquello que interviene en dar significado y sentido a lo que pensamos y conocemos.

La posición hermenéutica actual reconoce que los horizontes son culturales, esto es, relativos a culturas y mundos de vida de modo que ninguno puede ser tomado como universal y único. Cada realidad está significada en su propio horizonte. Ahora bien inevitablemente, la interpretación se hace en el horizonte del intérprete, esto es, en su sistema de paradigmas y teorías. Puede haber sido muy bien hecha según las reglas de la investigación más exigente, y, sin embargo, no haber llegado a la verdad de esa realidad sino haber producido un error aunque en el horizonte del científico no pueda ni siquiera ser advertido. Con la sola interpretación, el proceso hermenéutico está incompleto.

Para que el proceso hermenéutico pueda acceder a la verdad del acontecimiento, la interpretación ha de ser comprensiva, o lo que es lo mismo, la interpretación debe dar paso a la comprensión.

Llamamos comprensión en el proceso hermenéutico, a la interpretación realizada en el horizonte en el que la realidad interpretada tiene su significado propio. El investigador, por tanto, para lograr una comprensión adecuada de la realidad que investiga, ha de estar plenamente incorporado al horizonte de significación en el que tiene su sentido esa realidad. Como ese horizonte se soporta 
sobre una práctica de vida integral y orgánicamente estructurada de modo que constituye todo un mundo, un mundo-de-vida, de alguna manera el investigador tiene que vivirlo para que desde dentro, desde la posesión de sus claves y sus procesos de producir significado, pueda conocerlo y darle palabra. A esto lo llamamos en el CIP investigación convivida.

Ahora bien, puesto en marcha el proceso de interpretación-comprensión, un solo proceso hecho de esos dos momentos no en sucesión temporal sino simultáneos en interactuación, el intérprete-conocedor, el investigador, inevitablemente procede a integrar la realidad comprendida en el sistema de relaciones de significado que constituyen su aquí y su ahora, su temporalidad más concreta, en el que esa realidad adquiere su significado actual. En esto consiste fundamentalmente la aplicación, tercer momento con el que el proceso hermenéutico se completa. Tampoco este momento es separable de los dos anteriores pues se produce en simultaneidad e interacción con ellos.

Es esto lo que consideramos que nos ha permitido una comprensión de la Venezuela profunda, esto es, del sentido que dinamiza nuestro mundo-de-vida popular. En él tienen su sentido las historias de vida de los delincuentes de nuestro estudio. Con las claves de su mundo, que es el popular venezolano, es como han de ser interpretadas-comprendidas, conocidas y apalabradas.

De este modo aplicamos la hermenéutica a la investigación social.

\section{RESULTADOS MÁS IMPORTANTES}

Por estos caminos hemos llegado a poder elaborar una caracterización, o un perfil, del delincuente violento de origen popular en la Venezuela de hoy, desde su estructura y su proceso interior de estructuración, sobre la cual poder pensar en maneras y procedimientos de acción, en proyectos factibles de prevención y de corrección.

Empiezo por lo que en el proceso de estudio ha sido el final de todo nuestro trabajo, el concepto, el constructo resultante del largo estudio y que, una vez elaborado, se nos ha presentado como el núcleo integrador del fenómeno violencia delincuencial en cada uno de quienes la ejercen.

Si las vidas de nuestros sujetos las vemos desde ellas mismas, si penetramos en el interior de sus actores y nos detenemos a considerar las reglas de producción de su vivir cotidiano y el sistema de significados que subyace al discurrir de su vida, hallamos un principio de organización en unidad de sentido de sus múltiples acciones, experiencias y conductas que dota al todo de una racionalidad interior, de una lógica intrínseca, que conforma una manera específica de ejercer la vida.

Para dar nombre y contenido conceptual a esta integración en unidad hemos elaborado el constructo forma-de-vida.

Es cierto que la expresión "forma de vida" existe y se usa mucho y en muy variados sentidos. Por eso mismo hemos tenido que reelaborarla pues hemos 
llegado a ella no desde el puro lenguaje, desde una teoría ni desde la previa idea sino directamente desde las historias-de-vida de nuestros sujetos, desde sus prácticas y sus orientaciones vitales. La forma-de-vida violencia delincuencial es, pues, la estructura que constituye e in-forma toda la existencia del violento, una totalidad práxica, vivencial, conceptual, incluso semántica, en cuanto es una manera de dar significado al mundo que él vive, un modo de existencia, un estilo de vida, un sistema concreto de condiciones de vida en su actualidad y en su posibilidad futura de ser, una forma de interactuar con la sociedad, una manera de hacer, el discurrir de su proceso en el tiempo, esto es, una historia.

El constructo "forma-de-vida violencia delincuencial", nos ha permitido, además de sintetizar orgánicamente la multiplicidad del fenómeno, distinguir entre aquellos violentos que encajan perfectamente en él y que por lo mismo están constituidos como personas por esta forma-de-vida, de aquellos que han desarrollado una historia que circula un tanto o mucho, al margen de ella.

A los primeros los hemos llamado delincuentes violentos estructurales y a los segundos delincuentes violentos circunstanciales o accidentales.

Las diferencias entre unos y otros son muy importantes siendo la principal que los estructurales nunca salen de esa forma-de-vida en la que persisten hasta su muerte, generalmente violenta y temprana, mientras los segundos se recuperan como personas y se integran antes o después, sin necesidad de intervención especializada, a la normalidad social.

A partir de aquí hemos logrado, también, desarrollar tres temas discriminativos a los que sólo me referiré en algún momento de pasada y que merecerían un trato más amplio y detenido:

--Cómo se forma un delincuente violento

--Condiciones para salir de la violencia delincuencial

--Factores que salvan de caer en la violencia aun en las peores condiciones de vida personal.

La forma-de-vida violencia delincuencial posee un núcleo dinámico de integración que la dota de sentido y la constituye en estructura. Es lo que hemos identificado y definido como: centralidad autorreferente del yo subjetivo expansivo y sin límites como proyecto vital.

De esta vivencia y práctica del yo reciben su sentido todos los componentes de la forma-de-vida que, por eso, a su luz ha de ser comprendida, analizada y conceptualizada.

Así, todas las historias-de-vida de los violentos estructurales pueden ser pensadas como historias hechas de delincuencia y de violencia. La violencia está presente y actuante en todo su curso vital histórico. A estos sujetos desde muy pequeños la violencia los acompaña y se les va introduciendo en la estructura de su persona de modo que llega a constituir parte esencial de su vida, a convertirse para ellos 
en una manera "normal" de vivir. La violencia y el delito los van creando como personas concretas, van formando su vida. Se trata de un proceso de personalización por la violencia.

La afirmación ilimitada del yo, en su aspecto negativo, está expresada en la postura de no aceptar nada que pueda interpretarse como sometimiento. "Yo no quería que me estuvieran sometiendo", dice Héctor y así explica su decisión de empezar a "darle tiros a la gente. ¡Paj, paj!" (Moreno, A., et Al., 2009, 309). Son sus palabras.

Frank, por su parte, lo explicita igualmente con estas palabras: "lo quería matar, pues, porque la mente mía era esa, porque no me dejaba por nadie" (Moreno, A., et Al., 2009, 556).

¿Qué entienden ellos por sometimiento?

Todo lo que signifique algún tipo de control sea éste familiar, comunitario, social, legal, racional o afectivo.

Ante cualquier intento de control, se yergue, como defensa, el ataque brutal, extremoso, encaminado a la destrucción de eso que se percibe como limitante de la expansión del yo. La justificación última e indiscutible de toda conducta violenta está referida al dominio del yo personal, a la voluntad de poder sobre cualquier obstáculo, cualquier dificultad, cualquier adversidad. No hay nunca referencia a la familia, a sus necesidades, a su pobreza, a sus intereses ni a ningún grupo de cómplices, amigos o "panas".

En su aspecto positivo, esa afirmación ilimitada del yo estriba en exaltarlo ante todos, comunidad y sociedad, sin cortapisas. Esto consiste, sobre todo, en la búsqueda, logro y mantenimiento de lo que ellos llaman respeto.

Héctor lo expone muy bien: "to empezó porque también me sometían y... llegó un momento en que me ostiné... yo veía a los malandros que los respetaban, a todos los respetaban, y a mí esos chamitos me querían estar sometiendo y me cansé... me compré una pistola... a partir de ahí, me dieron una cachetá y le di cuatro tiros al chamo, a raíz de eso, empecé a cometer bastantes homicidios ... cuando tenía quince años, ya tenía seis homicidios" (Moreno, A., et Al., 2009, p. 312).

El respeto no es una condición o una actitud del violento hacia los demás sino al contrario, la actitud que él está en condiciones de imponer a los otros para con él por temor y sometimiento ineludible con lo que esos otros reconocen su superioridad e importancia indiscutidas. El respeto se obtiene por la imposición y exhibición de poder.

“Tenía el poder", nos dice Alfredo (Moreno, A., et Alt., 2009, 47) cuando estaba en lo más alto, por encima de todos los que con él delinquían y con capacidad para dominar a cualquiera que él quisiera, incluso a los agentes de la policía. El poder se sostiene en todos nuestros sujetos sobre el arbitrio y la fuerza caprichosa.

En todo esto consiste el respeto que viene ser el objetivo próximo y central de su 
orientación en la vida de violencia delincuencial.

Es interesante señalar que por distintos caminos y de manera independiente Verónica Zubillaga (2007, 582-583) coincide sustancialmente con nosotros en identificar la demanda y búsqueda de respeto en los jóvenes violentos, que son su población en estudio, como esencial en la construcción de la identidad de ese tipo de adolescentes.

"En el plano del significado, el respeto constituye un valor ideal que orienta la acción de estos jóvenes. En el plano de su traducción en las interacciones el respeto constituye un clamor personal de reconocimiento y de ascendencia que se supone adherido a la persona, concretamente a la identidad masculina”.

Pero se trata de una demanda de reconocimiento y ascendencia que se impone: "Los jóvenes exigen respeto pero no lo conceden. El respeto deja de representar la capacidad intersubjetiva de reconocimiento para constituir demanda pura de un sujeto que se impone".

Por éstos y otros múltiples caminos se organiza y decanta la forma-de-vida violencia delincuencial, que para los violentos estructurales se convierte, y así es percibida subjetivamente por ellos, como en un destino del cual ya no se pueden librar. De hecho funciona como tal.

Esta percepción la expresan con un término lleno de significado: la vía.

En el ámbito de absoluta arbitrariedad egocentrada en el que discurre su vida, el violento, en aparente paradoja, se siente juguete del destino, esto es, de una fuerza anónima y externa que lo domina y rige su existencia. Esto le sirve al mismo tiempo de excusa y alibi para sus crímenes. El destino le libra de toda responsabilidad, no tanto ante sí mismo, pues en él el crimen acaba por no producir ningún sentimiento de culpa siendo más bien una hazaña de la que se siente orgulloso, sino ante los demás.

Lo que se nos presenta como total libertad, como absoluta gana ejercida, en cuanto realización de la más espontánea arbitrariedad, sin control ni límites impuestos, paradógicamente conforma una línea de acción en la vida muy rígida en sí misma de la que el sujeto siente que no se puede salir, a la que se percibe indisolublemente ligado. La extrema libertad como inevitable esclavitud. En esto consiste la vía

Volviendo a los núcleos centrales de significado de los delincuentes violentos, la ya señalada demanda y no concesión de respeto va encaminada a lograr la afirmación ilimitada de su yo expansivo y con ella se confunde. De aquí que todo su lenguaje y todo su estilo narrativo estén centrados en ese yo que todo lo invade y que se propone como protagonista absoluto en su grupo, en la comunidad en la que vive y de toda clase de hazañas y aventuras excepcionales y arriesgadas. Centrados ellos en sí mismos desde un principio, nunca se descentran.

¿Dónde está, de dónde viene, cual es su punto de partida, cuál la fuente originaria de semejante posición ante la vida? 
De la investigación, resulta muy claro que no está en la pobreza ni en las circunstancias ambientales adversas vividas por los sujetos el origen y el movimiento motivacional primario de toda su forma violenta de vida. Ninguno, en efecto, cuando empieza ni durante toda su trayectoria de delito, roba artículos de necesidad. Sus hurtos van dirigidos a adquirir objetos de representación, productos de lujo que den prestigio ante los demás, preponderancia, capacidad de dominio, que los igualen con los más privilegiados de la sociedad y del mundo del hampa.

El caso de José es ejemplar. El, que se define a sí mismo como ladrón profesional, --“yo José Gómez soy ladrón; fui ladrón de toda la vida" (Moreno, A., et Al., 2009, 275) - viaja desde El Dorado hasta Caracas (unos novecientos kilómetros) sin un centavo en el bolsillo porque lo que tenía ahorrado en el penal lo dilapidó en una semana de libertad, y, sin embargo, no se le ocurre robar para conseguir el pasaje o la comida. Ya en Caracas, camina desde El Silencio hasta Petare (quince kilómetros, por lo menos) pues no tiene moneda ni para pagar el autobús y en todo ese trayecto, cuando pensaríamos que como ladrón sería lógico que cometiera algún asalto o atraco, no se le ocurre ni remotamente hacerlo.

En ellos, el delito no cumple la función de satisfacer necesidades vitales sino de poder y de eso que ellos, como ya he dicho, han llamado respeto.

El factor originario principal y fundamental que hemos encontrado ha sido otro: el sufrimiento padecido en las primeras etapas de la vida, esto es, la violencia recibida que se transforma muy pronto en violencia administrada hacia los demás

La violencia recibida no tiene necesariamente la forma de crueldad o maltrato físico o de golpes fuertes y abundantes. La violencia que desde muy niños padecen estos sujetos toma la forma del abandono con múltiples variaciones: descuido, desatención, rechazo vivido profundamente. La constante en su vida es que sus historias pueden definirse como historias de ausencias claves. Sobre todo, ausencia de madre significativa, tal como la exige el mandato cultural del mundo-de-vida popular venezolano, de afecto positivo, de relaciones vinculantes, de atención profundamente amorosa. Esto conforma un trasfondo de dolor inscrito en las raíces de la persona, dolor que pocas veces y sólo fugaz y superficialmente pasa a la consciencia, un trasfondo de violencia padecida que sustenta su disposición a la violencia actuada.

Hay, pues, en el fondo de todo una relación muy dañada, especialmente con la madre. Esto es característico si tenemos en cuenta que en el mundo-de-vida popular venezolano las familias son predominantemente matricentradas, en las que la figura materna lo es todo y constituye lo verdaderamente estructural del núcleo familiar mientras el padre es una figura tangencial que no tiene real significación para los hijos. Al fallar la madre, a menos que no sea sustituida eficazmente por una abuela u otra figura femenina, no hay compensación posible. El niño, entonces, empieza a manifestar su violencia en la casa, en la escuela, por el vecindario en el que encuentra abundante caldo de cultivo en la pandilla de coetáneos y en el ejemplo de los delincuentes mayores. Luego, ya adolescente, la actúa en las calles de la ciudad, en los primeros asesinatos, en las primeras experiencias de reformatorio 
y de joven adulto hasta su temprana muerte -no suelen vivir más de veinticinco años-de mil maneras y en la cárcel. Es la vía.

Para los delincuentes violentos circunstanciales el proceso es muy distinto. Ante todo, su experiencia familiar temprana es fundamentalmente positiva. Puede haber en alguno de ellos algún tipo de problema hogareño pero no tal que los impulse a la violencia temprana y a la huida hacia la calle. Su iniciación en el delito coincide con la rebeldía adolescente y su incorporación al grupo de coetáneos del ambiente barrial en el que viven. Mientras los estructurales no logran permanecer en la escuela, éstos se mantienen en ella hasta finalizar por lo menos la primaria. Caen en delitos, incluso en homicidios, pero manifiestan sentimientos de culpa y la experiencia de la cárcel, en vez de sumergirlos más en la violencia como sucede con los otros, les produce el deseo profundo de no volver y encuentran que la manera de lograrlo es cambiar de vida. Esto se reafirma cuando consiguen una mujer con la que logran establecer pareja estable. Los estructurales, en cambio, nunca establecen pareja aunque multiplican sus experiencias sexuales y riegan hijos por todas partes.

La atención y educación recibida antes de la adolescencia en la familia y en la escuela y la capacidad mantenida de formar pareja se muestran como los factores determinantes para que un sujeto nunca entre de lleno en la forma-de-vida violencia delincuencial y no pertenezca a su estructura.

El caso de Ismael nos confirma en lo significativa que es para librarse de caer en la forma-de-vida violencia delincuencial, la relación humana profunda con una figura materna en la primera infancia. En efecto: desde el momento de su abandono a los tres años encuentra figuras sustitutas de la madre o lo que pueden considerarse como madres concretas identificables como tales.

Si bien pasa sus primeros años en instituciones del Estado, allí lo acogen funcionarias que, saliéndose del reglamento y guiadas por lo que la cultura popular le asigna a una mujer, se toman a pecho el papel de esa figura fundamental. Pasa luego a instituciones privadas pero también en ellas encuentra, primero durante la primaria y luego en la adolescencia, el ámbito relacional que le permite integrarse al grupo de iguales y establecer al mismo tiempo contactos afectivos e identificatorios con las personas adecuadas para guiarlo y orientarlo hacia un futuro sano y productivo.

\section{CONCLUSIONES Y REFLEXIONES}

Terminaré esta breve síntesis informativa de nuestro estudio, mientras dejo fuera muchos e importantes aspectos, delineando brevemente algunas características significativas del delincuente asesino joven en nuestros días, por ser el que predomina en el mundo del delito violento y el más peligroso para cualquier ciudadano.

Hemos podido seguir en nuestro trabajo, e inesperadamente, lo que podría considerarse la evolución histórica de la violencia delincuencial en Venezuela 
desde los años cincuenta hasta nuestros días. Así, la hemos dividido en tres etapas: etapa antigua o del malandro viejo, como se lo llama en los barrios, etapa media y etapa actual o del malandro nuevo. Las diferencias son muchas e indicativas tanto para el tratamiento como para la prevención pero sobre ellas no me puedo detener.

Me parece, sin embargo, importante destacar lo que hemos llamado el proceso de autonomización de la violencia delincuencial que se ha seguido desde la mitad del siglo veinte hasta nuestros días.

Con este nombre se quiere decir que la delincuencia, en tiempos de los "antiguos" no era autónoma de la sociedad, de la comunidad barrial, de la opinión de los ciudadanos. Eso no impedía que el delincuente delinquiera pero para poder hacerlo tenía que observar ciertas formas, resguardarse, actuar en ciertos espacios y no en otros, en ciertos tiempos y no en otros, etc. Cuando para delinquir tenía que conservar ciertas maneras, estaba sometido a un determinado control. Era un cuerpo enfermo, peligroso, dañino, todo lo que se quiera, de la sociedad pero le pertenecía como le pertenecen los alcohólicos, los locos, los retrasados mentales. Para él, la sociedad había elaborado sus mecanismos de control, de aislamiento, de reclusión e incluso de reintegración. En esos espacios se desenvolvía la vida del delincuente cuidándose, acomodándose, aprovechando las fisuras y deficiencias, eludiendo o manipulando los controles, etc. De todos modos, no tenía manera de autonomizarse totalmente de ellos.

En estos momentos, en cambio, los "nuevos" se han autonomizado por completo. Ninguno de esos dispositivos ejerce presión alguna sobre ellos. Pero además, se trata de una autonomía de todo rastro de los valores de la cultura, de todos los significados del mundo-de-vida popular, de todo lo que se ha conceptualizado como "humano" en la tradición y de lo que en el "antiguo" siempre quedaban huellas. Esta autonomía del "nuevo" es además, un total desarraigo. No se sostiene sobre nada, ni sobre la familia, ni sobre la madre, ni sobre el amigo, ni sobre la tierra, ni sobre la naturaleza, ni sobre la dignidad, ni sobre la humanidad, sólo sobre su propio mecanismo de acción encaminado a la satisfacción inmediata del deseo, de todo deseo, tanto de goce como de muerte. La muerte de los demás es para ellos una hazaña de la que se glorían por el asesinato mismo. El énfasis lo ponen en la capacidad de asesinar y asesinar mucho. Cuantos más muertos tenga encima y más joven sea el sujeto, más digno de admiración y más valioso es, con lo que se equipara y aun puede superar a los más "cartelúos". Esto lo percibe incluso la gente común. "Quien lo mató es uno de los jóvenes que lo que buscan es ganar "fama" en el barrio", dice Rafael, amigo de una víctima, según testimonio reciente de la prensa (Iglesias, M. I., 2008).

Para ellos la muerte del otro es una decisión simple. Está más allá del odio y del amor. No necesita explicación, procesamiento ni racional ni afectivo. Se ejecuta y ya está. Se les puede aplicar lo que decía uno de los niños soldados de las terribles guerra africanas (Sanchiz, 2004) "a los diez años yo era una máquina de matar... nada nos infundía respeto". Esto los sitúa fuera de toda preocupación moral. Javier Marías lo ha expresado muy bien con dos preguntas en "Tu rostro 
mañana, veneno y sombra y adiós” $(2007,19)$ : ¿Por qué no se puede? ¿Por qué no se puede ir por ahí pegando y matando, según has dicho?”.

He expuesto sintéticamente hasta aquí la dinámica psicológica del delincuente violento de origen popular, los móviles que rigen su singular subjetividad. Con ello no estoy negando la importancia de los factores propios de la estructura social, económica y ambiental que también aparecen en nuestro estudio. Estos, sin embargo, no actúan de la misma forma en todas la personas. Sólo en quienes poseen disposiciones propias enraizadas en su historia, desde que ésta arranca, su incidencia los abre al delito y a la violencia extrema. En la Venezuela actual a todo ello se añade la ausencia, en la práctica cotidiana, del Estado apenas uno deja las vías de la ciudad y se adentra por las calles de cualquier barrio en el que por lo mismo impera no sólo la impunidad más absoluta sino también el total descontrol sobre las drogas y las armas, ambos artículos muy fáciles de conseguir distribuidos además, con demasiada frecuencia, por los mismos agentes de los distintos organismos policiales y militares.

¿Qué hacer? Nuestro estudio no presenta recetas de solución porque, y así lo decimos al final, "de recomendaciones está empedrado el camino que ha conducido a esta violencia como de buenas intenciones el del infierno" (Moreno, A., et Al., 2009, 894).

Si algo, sin embargo, se puede indicar, dejando de lado muchos otros aspectos que de nuestro trabajo se pueden deducir, y limitándome a uno sólo pero que me parece de la mayor importancia, es que hay que prevenir y prevenir en el seno de la familiar popular.

Hay familias en las que se forman los futuros criminales. Sobre éstas, que pueden ser a tiempo identificadas, la sociedad y el Estado al servicio de ella, ha de ejercer intervenciones de asesoramiento, apoyos de todo tipo desde el económico hasta el psicológico y sustituciones cuando sea el caso, siempre teniendo en consideración el mundo-de-vida y la cultura popular a la que pertenecen y penetrando a fondo en la comprensión de los procesos que se dan en la familia matricentrada los cuales son muy distintos de los que conocemos como propios de las familias nucleares tradicionales.

\section{REFERENCIAS BIBLIOGRÁFICAS}

Aristóteles (1973), Metafísica, en : Obras Completas, Aguilar, Madrid.

Briceño León, R. (2005), Dos décadas de violencia en Venezuela, en: Fundación

Venezuela Positiva, Violencia, Criminalidad, Terrorismo, Caracas.

(2007), Violencia urbana en América Latina, Espacio Abierto, vol. 16, julioseptiembre, 541-574, Maracaibo.

(2010), en: El Nacional 31 diciembre, Caracas.

Briceño León, R., compilador, (2001)Violencia, sociedad y justicia en América 
Latina, CLACSO, Buenos Aires.

Briceño León, R. et Alt., (1997), La emergente cultura de violencia en Caracas,

Revista de Economía y Ciencias Sociales, UCV, Caracas

(2008), Inseguridad y violencia en Venezuela, Alfa, Caracas

Briceño León, R.. y Pérez Perdomo, R., (2002), La violencia en Venezuela, un

fenómeno capital, en: BID: Asalto al Desarrollo, Washington.

Catani, M,, Mazé, S., (1982) Tante Suzanne, Librairie des Méridiens, Paris.

Cedeño, L. (2010), en: El Nacional, 18 septiembre, Caracas

Cisneros, A., Zubillaga, V., (1997), La violencia desde la perspectiva de la víctima, Espacio Abierto, v. 6. $\mathrm{n}^{\mathrm{o}} .1$

Del Olmo, R. (1997), La conexión criminalidad violenta/drogas ilícitas Cisneros, A., Economía y Ciencias Sociales, no 2-3, UCV.

EFE agencia (2011), Violencia record en Venezuela, 2 febrero, www.unpais.com

España, L. P. (1994), Introducción, La Violencia en Venezuela, en: Varios, La violencia en Venezuela, Caracas, Monte Avila.

Ferrándiz, F., (2005), Venas abiertas: africanos y vikingos entre los jóvenes

Espiritistas venezolanos. En: Ferrandiz y Carles, Jóvenes sin tregua, 171-185, Barcelona, Anthropos.

Ferrarotti, F., (1981), Storia e storie di vita, Laterza, Bari.

Iglesias, M. I., (2008), Adolescentes asesinaron a mecánico para ganar fama, www.eluniversal.com/2008/8/31

Instituto Nacional de Estadística (2006), Informe, Encuesta Nacional de Victimización y Percepción Policial 2006, Noviembre 2006 (2010), Encuesta Nacional de Victimización y Percepción de Seguridad Ciudadana 2009 (ENVPSC-2009), Documento Técnico, Caracas mayo 2010

Marías, J., (2007), Tu rostro mañana, 3, veneno y sombra y adiós, Madrid, Santillana Martínez, M. (1999), La Nueva Ciencia, Trillas, México

Molina, T., (2008), Estudio, El Nacional, Sucesos, 20-8-2008.

Molina, T., (2010), Estudio, El Nacional, Sucesos, 31-12-2010

Moreno, A., (2006), Pastor celestial, rebaño terrenal, lobo infernal, Bidanco, Caracas 
(2007) La familia popular venezolana, Gumilla-CIP, Caracas

(2008), El Aro y la Trama: episteme, modernidad y pueblo, Convivium,

Miami

(2008), ¿Padre y Madre?, CIP, Caracas

Moreno A., et Alt. (2009), Y salimos a matar gente, Caracas, CIP

(1998), Historia-de-vida de Felicia Valera, CONICIT, Caracas

(2002), Buscando Padre, Universidad de Carabobo, Valencia

Moreno, A. y González, V. (2008), La Orientación como Problema, CIP. Caracas.

Pedrazzini, Y., Sánchez, M., (1990), Nuevas legitimidades y violencia urbana en

Caracas, Nueva Sociedad, sept.-oct.

(1992), Malandros, bandas y niños de la calle, cultura de urgencia en las

metrópolis latinoamericanas, Vadell Hermanos, Caracas

Pérez, M., (2010), Vida cotidiana y familia popular venezolana, Bidanco, Caracas

Rodríguez, G., (2010), Tras quince planes de seguridad, en: "El Universal”, 17marzo.

Sanchiz, I., (2004), Meter, un niño soldado en Sierra Leona, la Vanguardia, jueves

23 de diciembre, Barcelona, España.

Thomas, L. V., (1982), Préface, en: Catani,M., "Tante Suzanne”, Librairie des

Meridiéns, Paris

Ugalde, L. (1993), Presentación, en: Varios, La violencia en Venezuela, Caracas, Monte Avila

Vethencourt, J. L., (1990, 2008), Psicología de la violencia, Akademus, enero-junio, 41-56.

WHO (1996), Global Consultation on Violence and Health, en: OMS, Violence: $A$ public health priority, Ginebra.

(2002), Informe Mundial sobre la Violencia y la Salud, OPS, OMS, Washington

Zubillaga, V. (2007), Los varones y sus clamores: los sentidos de la demanda de respeto y las lógicas de la violencia entre jóvenes de vida violenta de barrios de Caracas, Espacio Abierto, vol. 16, julio-septiembre, 577-608, Maracaibo.

(2008), La culebra, Akademus, enero-junio

(1997), La violencia desde la perspectiva de la víctima,

Espacio Abierto, v. 6. $\mathrm{n}^{\mathrm{o}} .1$ 